\title{
Waste Foundry Sand as Permeable and Low Permeable Barrier for Restriction of the Propagation of Lead and Nickel Ions in Groundwater
}

\author{
Ayad A. H. Faisal $\left(\mathbb{D},{ }^{1}\right.$ Zaid Abed Al-Ridah, ${ }^{2}$ Laith A. Naji ${ }^{(D)},{ }^{3}$ Mu. Naushad $\left(\mathbb{D},{ }^{4}\right.$ \\ and Hamed A. El-Serehy ${ }^{5}$ \\ ${ }^{1}$ Department of Environmental Engineering, College of Engineering, University of Baghdad, Baghdad, Iraq \\ ${ }^{2}$ College of Water Resources Engineering, Al-Qasim Green University, Babylon, Iraq \\ ${ }^{3}$ Technical Instructors Training Institute, Middle Technical University, Baghdad, Iraq \\ ${ }^{4}$ Department of Chemistry, College of Science, Bld. No. 5, King Saud University, Riyadh, Saudi Arabia \\ ${ }^{5}$ Department of Zoology, College of Science, King Saud University, Riyadh, Saudi Arabia \\ Correspondence should be addressed to Ayad A. H. Faisal; ayadabedalhamzafaisal@yahoo.com
}

Received 24 April 2020; Revised 18 June 2020; Accepted 25 June 2020; Published 31 July 2020

Academic Editor: Hakan Arslan

Copyright (c) 2020 Ayad A. H. Faisal et al. This is an open access article distributed under the Creative Commons Attribution License, which permits unrestricted use, distribution, and reproduction in any medium, provided the original work is properly cited.

\begin{abstract}
This work aims to investigate the ability of using waste foundry sand (WFS) resulting as inexpensive by-product from steel industry in the low permeability barrier (LPB) and permeable reactive barrier (PRB) technologies for restriction of the movement of lead and nickel ions in the groundwater. Outputs of flask and tank tests certified that this material could capture these ions with sorption efficiency greater than $95 \%$ at time, $\mathrm{pH}$, sorbent dosage, and speed equal to $60 \mathrm{~min}$, 4 for lead and 6 for nickel, $2.5 \mathrm{~g} /$ $100 \mathrm{~mL}$, and $250 \mathrm{rpm}$, respectively. Sorption isotherm measurements were represented in a good manner by Langmuir model in comparison with Freundlich model with coefficient of determination $\left(R^{2}\right)$ greater than 0.99 . So, the chemisorption was the predominant mechanism which could be supported by $\mathrm{O}-\mathrm{H}, \mathrm{H}-\mathrm{O}-\mathrm{H}, \mathrm{C}-\mathrm{O}, \mathrm{O}-\mathrm{Si}-\mathrm{O}$, and Si-O functional groups based on the Fourier transform infrared analysis. The maximum sorption capacity of WFS was 13.966 and $4.227 \mathrm{mg} / \mathrm{g}$ for lead and nickel ions, respectively, with corresponding affinities equal to 0.647 and $0.099 \mathrm{~L} / \mathrm{mg}$. Measurements signified that the hydraulic conductivity of WFS was $3.8 \times 10^{-7} \mathrm{~cm} / \mathrm{s}$ which satisfies the requirements of LPB. To obtain the acceptable values of permeability and reactivity, PRB was prepared from mixing $18 \%$ WFS with $82 \%$ filter sand. COMSOL software was able to simulate the measurements of twodimensional tank packed with Iraqi soil aquifer in combination with WFS-LPB and WFS-filter sand PRB. Thicker barriers have a high ability in the protection of locations in the down-gradient side because their longevity increased dramatically with increase of barrier thickness.
\end{abstract}

\section{Introduction}

The "water found beneath the surface of the ground and seeped down from the surface by migrating through the soil matrix and spaces in geologic formations" is common definition of the groundwater [1]. This water can be utilized extensively for domestic, industrial, commercial, and agricultural uses; however, previous studies certified that the $56 \%$ of water supply in USA comes from groundwater. So, it is expected that this resource can be exposed to severe contamination by organic and inorganic compounds due to natural and anthropogenic sources [2-5]. This contamination forms serious challenge for nations depending primarily on the groundwater as source for living requirements; consequently, many authorities consider this contamination as major environmental issue. Leakage of hazardous compounds from waste ponds, landfills, underground storage tanks, transportation pipelines, pesticides rinse formulation areas, and others is the main source of contaminants reaching the groundwater $[6,7]$. Lead $\left(\mathrm{Pb}^{+2}\right)$ and nickel 
$\left(\mathrm{Ni}^{+2}\right)$ are the most abundant metals in the crust of the Earth and they are used since prehistoric times. The most serious harmful health effects resulting from $\mathrm{Pb}^{+2}$ and $\mathrm{Ni}^{+2}$ metals are represented by damage of kidneys and blood, central nervous system, and nasal cavity, as well as larynx and lungs [8-10].

Reclamation of the groundwater quality to satisfy the acceptable environmental regulations is considered a difficult and expensive problem that is used frequently as limiting factor for closing of polluted locations. Historically, pump-and-treat technology is the traditional method used for remediating of contaminated groundwater. It is based on the pumping of groundwater to the treatment unit present on the surface of ground. Treatment can be achieved by adsorption, ion exchange, chemical precipitation, electrodeposition, or any other efficient method and, then, the remediated water must be discharged to the storm drain or subsurface medium. Previous researches applied on this technique proved that the pump-and-treat method is not dependable because of the high cost and limited performance in the reclamation of groundwater with acceptable periods of time [11].

For waste containment in subsurface environment, low permeability barrier (LPB) in conjugation with extraction wells can be applied to restrict the on-site water flow and to prevent the off-site transport of chemical species. Large quantities of water can be infiltrated into sanitary landfill through irrigation or from rainfall, so moving water in the layers of solid wastes will generate the leachate which accumulated on the liner. The failure of this liner for any reason will lead to leachate reaching surrounding environment and this will pollute large quantities of groundwater and soil. Consequently, containment system is required to protect the subsurface regime and this system must not consist of bottom liner only but also cover for landfill in order to prevent the water infiltration [12]. Another example of engineering solution for groundwater protection is represented by using bentonite cut-off with peripheral drainage for collecting of leachate as one utilized in the large embankment sanitary landfills, Radiowo, Poland [13].

Laboratory testing program to evaluate the utilization of green sands from grey iron foundries as LPB was presented. Specimens of this sand were compacted at different values of compactive efforts and water contents; then, relationships between compaction water content, hydraulic conductivity, and dry unit weight have been identified. Results showed that the foundry green sands are viable materials for constructing low hydraulic conductivity barrier layers for use as liners and covers in landfills, ponds, and sewage lagoons [14]. Hydraulic and geochemical study on 2 materials - natural clay (AN) and a regenerated material made up of a sand-bentonite (SB) mixture-was introduced. The hydraulic part proved that a $10 \%$ industrial bentonite content mixed with sand offered hydraulic properties that are similar to those of $\mathrm{AN}$ material and are lower than the required standards. Langmuir model was able to identify the adsorption capacities of mixture with selectivity ranged in the order of $\mathrm{Pb}>\mathrm{Cu}>\mathrm{Cd}>\mathrm{Zn}$ [15]. The ability of geosynthetic clay liners (GCLs) to prevent contaminant transport towards groundwater when they are used in the landfill barrier design was studied. The hydration of two GCL products placed in contact with clay subsoils at different initial moisture contents was described under both isothermal conditions at room temperature and daily thermal cycles. Results revealed that GCLs undergoing daily thermal cycles absorbed much less moisture over time than the GCLs kept at constant room temperature with ratio of 1 : 4 [16]. Batch and continuous tests with mathematical modeling proved the ability of the Iraqi bentonite as LPB in the capturing of cadmium ions from aqueous solutions and restriction of contamination propagation [17].

As alternative for pump-and-treat method, permeable reactive barrier $(\mathrm{PRB})$ technology proved its ability in the remediation of groundwater contaminated with a wide range of chemical species. So, $\mathrm{PRB}$ is considered a promising approach because the treatment occurs on-site with low energy and acceptable costs for operation, monitoring, and maintenance. Materials of PRB should persist (i.e., not soluble and remain reactive) with time and be available with acceptable cost [18]. Activated carbon can be used as a highly effective reactive material in $\mathrm{PRB}$, but it is relatively expensive [19]. New orientation in studies has been raised towards the utilization of by-products or low-cost natural substances like fly ash, cocoa shell, calcified seaweed, and the natural clinoptilolite [20], limestone, recycled concrete, blast furnace slag, lime and fly ash [21], red mud [22], sewage sludge [23-25], iron slag [26], waste foundry sand [27], zerovalent iron [28], cement kiln dust [29], olive pips $[30,31]$, and waterworks sludge $[32,33]$. For example, iron slag was tested in the batch mode to find its ability in the remediation of water contaminated with lead ions; however, the results proved the efficacy of this iron as PRB especially that the estimated value of retardation factor reached 500000 for equilibrium concentration of $5 \mathrm{mg} / \mathrm{L}$ [26].

Surveys reported that the $3 \times 10^{6}$ tons of WFS were emitted through 2012 in Brazil [34]; in USA, $6 \times 10^{6}-10 \times 10^{6}$ tons of WFS were generated per year and just $15 \%$ of this quantity can be recycled while the residual is disposed of to the landfill [35]; in India, the yearly production of this waste reached approximately $1.71 \times 10^{6}$ tons [36]; however, the dumping of WFS by foundries can cause environmental degradation [37]. For production of copper, iron, and aluminium castings in the UK, there are more than four hundred fifty foundries that generate $1 \times 10^{6}$ tons of WFS per year [38]. Consequently, this waste must be stockpiled outside the foundries especially for limited storage space; in addition, this waste can be an obstacle for production when the quantities of WFS exceed the on-site storage structures. Moreover, the leaching of contaminants from waste stockpiles has negative environmental impacts on the surrounding environment; therefore, finding alternative outlets for management of arising waste is pressing need. Hence, the main aims of this work are (1) identification of the interaction of WFS and water contaminated with lead and nickel ions based on the set of batch tests to specify the best conditions required to achieve the maximum removal efficiency for these ions, (2) specifying the functional groups 
present on the WFS that enhanced the removal process, and (3) using two-dimensional tank tests simulated mathematically by COMSOL Multiphysics 3.5a (2008) software to find the ability of WFS utilization in LPB and PRB to restrict the mentioned ions migration in the contaminated groundwater.

\section{Experimental Work}

\subsection{Materials and Contaminants}

(1) Iraqi sandy soil was used as porous medium in the experiments conducted in this study. Table 1 presents the composition and properties of this soil which had a particle size distribution ranging from 0.075 to $1.18 \mathrm{~mm}$ and median grain size $\left(d_{50}\right)$ of $0.43 \mathrm{~mm}$.

(2) Waste foundry sand was obtained from Nasr Company for Mechanical Industries, Baghdad, Iraq. This sand had the same particle size distribution of Iraqi sandy soil mentioned previously with $d_{50}$ of $0.33 \mathrm{~mm}$. It primarily consisted of silica with percentage reaching $94 \%$ and the remaining is represented by minerals of clay because the bentonite forms the primary component of the WFS. Table 1 presents the main properties of this waste and it seems that the value of the hydraulic conductivity coefficient was very low $\left(=3.8 \times 10^{-7} \mathrm{~cm} / \mathrm{s}\right)$ and nearly equal to conductivity of the clay; so, this sand can be tested as LPB. To use WFS as PRB, hydraulic conductivity must be increased with permeable material. In this direction, filter sand (FS) with $d_{50}$ of $0.44 \mathrm{~mm}$ was chosen and it was mixed with WFS with several proportions selected randomly. However, PRB consisting of $18 \%$ WFS and $82 \%$ FS by weight was adopted because the hydraulic conductivity of this mixture $\left(=5.1 \times 10^{-3} \mathrm{~cm} / \mathrm{s}\right)$ was greater than that of ambient aquifer (i.e., Iraqi sandy soil) which has conductivity equal to $2.2 \times 10^{-3} \mathrm{~cm} / \mathrm{s}$ as mentioned in Table 1.

(3) Contaminants, lead and nickel, were selected to contaminate the aqueous solution with concentration of $1000 \mathrm{mg} / \mathrm{L}$ by adding $1.59 \mathrm{~g}$ of lead nitrate or $4.95 \mathrm{~g}$ of nickel nitrate to $1 \mathrm{~L}$ distilled water at room temperature. The required concentration of any metal can be obtained by dilution of prepared solution; however, drops of $0.1 \mathrm{M} \mathrm{HNO}_{3}$ or $\mathrm{NaOH}$ must be added to adjust the $\mathrm{pH}$ of the solution.

2.2. Batch Experiments. Four stages are applied in the batch experiments to specify the values of initial $\mathrm{pH}$, agitation time, sorbent quantity, and shaking speed required to achieve the maximum removal efficiency for lead and nickel ions present in certain concentration. These stages can be summarized as below:

(1) First stage: It requires fixing the values of sorbent quantity, initial metal concentration $\left(C_{o}\right)$, and shaking speed at $2.5 \mathrm{~g} / 100 \mathrm{~mL}, 50 \mathrm{mg} / \mathrm{L}$, and
TABLE 1: Composition and properties of the Iraqi soil and WFS used in the present study.

\begin{tabular}{lcc}
\hline \multirow{2}{*}{ Property } & \multicolumn{2}{c}{ Value } \\
& Iraqi soil & WFS \\
\hline Particle size distribution (ASTM D 422) & & \\
Sand (\%) & 96.5 & ------ \\
Silt and clay (\%) & 3.5 & \\
Hydraulic conductivity (cm/s) & $2.2 \times 10^{-3}$ & $3.8 \times 10^{-7}$ \\
Cation exchange capacity (meq/100 g) & 2.13 & 109.4 \\
pH & 7.7 & ------ \\
Organic content $(\mathrm{ASTM} D$ 2974, \%) & 0.26 & ---- \\
Bulk density $\left(\mathrm{g} / \mathrm{cm}^{3}\right)$ & 1.39 & 1.43 \\
Surface area $\left(\mathrm{m}^{2} / \mathrm{g}\right)$ & ----- & 5.94 \\
Porosity & 0.47 & 0.43 \\
\hline
\end{tabular}

$250 \mathrm{rpm}$, respectively, with variation of initial $\mathrm{pH}$ $(3-7)$ and agitation time $(\leq 180 \mathrm{~min})$. The main outputs of the present stage are determined the best values of contact time and initial $\mathrm{pH}$ that are identical to the maximum value of efficiency; however, these values will stabilize in the next stages.

(2) Second stage: The sorbent dosage with the range of $0.5-4 \mathrm{~g} / 100 \mathrm{~mL}$ was added to the aqueous solution contaminated with same $C_{o}$ mentioned in the first stage. Under the agitation speed equal to $250 \mathrm{rpm}$, the best value of sorbent dosage is specified based on the same criteria adopted in the previous stage. This value with magnitudes of contact time and initial $\mathrm{pH}$ identified from the first stage can be applied for tests in the third and fourth stages

(3) Third stage: By adopting the best values of $\mathrm{pH}$, time, and sorbent dosage, the effect of $C_{o}$ was studied with values varied from 50 to $250 \mathrm{mg} / \mathrm{L}$ at same value of speed mentioned in previous stages.

(4) Fourth stage: The last stage aims to specify the best value of agitation speed and this required changing its value from zero to $250 \mathrm{rpm}$ by applying the results of the previous stages.

In the aforementioned experiments, flasks of $250 \mathrm{~mL}$ were utilized and volume $(V=100 \mathrm{~mL})$ of contaminated solution with certain sorbent quantity $(\mathrm{m})$ must be placed in each flask. The solutions in the flasks should be maintained on the orbital shaker (Thermolyne, Maxi-Mix III, Type: 65800 , USA) to ensure the best contact between the solution and solid phase. Thereafter, certain volume from each flask was taken and filtered using filter paper; however, atomic absorption spectrophotometer (AAS, Sens AA, Australia) was the apparatus utilized to measure the final concentration $\left(C_{e}\right)$ of metal ions in the solutions after filtration. Mass balance equation was applied to calculate the quantity of metal ions retained on the sorbent $\left(q_{e}, \mathrm{mg} / \mathrm{g}\right)$ as follows [39]:

$$
q_{e}=\left(C_{o}-C_{e}\right) \frac{V}{m}
$$

2.3. Continuous Experiments. Two-dimensional tank was manufactured from acrylic glass $(6 \mathrm{~mm}$ thick) with 
dimensions of 100,40 , and $10 \mathrm{~cm}(L \times W \times H)$ as schematically plotted in Figure 1(a). The design of this tank is taken from the previous study of present authors [17, 27], and it was used to perform the propagation of the contaminant plume through the packed aquifer bed in the presence of LPB (Figure 1(b)) or PRB (Figure 1(a)). The tank was divided into three compartments by using two perforated plates of acrylic glass covered with filter paper. The middle compartment is the location of Iraqi sandy soil aquifer and the water level within this bed can be controlled by influent and effluent chambers where the length of each one is equal to $10 \mathrm{~cm}$.

Flow rate of $100 \mathrm{~mL} / \mathrm{min}$ was applied through the soil bed with aid of constant head tank, float valve, and flow meter where the interstitial velocity is equivalent to $0.5 \mathrm{~cm} /$ min. The locations of the sampling ports were fixed by sampling plate situated on the top face of the tank and the shape of this plate is plotted in Figure 1(c). Five sampling ports (black dots in Figure 1(c)) are selected on the centerline of the tank in the longitudinal direction to monitor the migration of $\mathrm{Pb}^{+2}$ and $\mathrm{Ni}^{+2}$ plume. Stainless needles were utilized to collect periodically the aqueous samples after packing the middle compartment with $5 \mathrm{~cm}$ of aquifer and barrier in configuration appeared in Figure 1. These samples ( $\approx 2 \mathrm{~mL}$ for each one) were analyzed by AAS to measure the concentrations of the $\mathrm{Pb}^{+2}$ and $\mathrm{Ni}^{+2}$. In addition, tracer experiment using the same approach adopted by previous studies $[27,40]$ was applied to specify the longitudinal dispersion coefficient $\left(D_{L}\right)$ for Iraqi sandy soil and WFS.

\section{Modeling of Measurements}

3.1. Sorption Measurements. The modeling of the sorption results obtained from experimental measurement means finding the relationship between the quantity of the chemical element removed from aqueous solution (i.e., sorbed on solid phase, $q_{e}$ ) and its concentration remaining in the solution $\left(C_{e}\right)$. This relationship is measured under certain value of temperature and initial $\mathrm{pH}$ of aqueous solution for equilibrium statue; so, it is named "equilibrium isotherm" relation. Literatures developed a set of models that describe this relationship like Freundlich, Langmuir, Elovich, Temkin, Kiselev, and Hill-de Boer. Intensive information about the assumptions adopted in the derivation of these models and all specifications required to implement these models are available in the previous studies like [41, 42]. The description of the sorption data in this work is fitted with Freundlich and Langmuir isotherms using linear regression because they consider earliest and familiar models. These two models have the following forms:

$$
\begin{aligned}
& \text { Freundlich: } q_{e}=K_{F} C_{e}^{1 / n}, \\
& \text { Langmuir }: q_{e}=\frac{q_{\max } b C_{e}}{1+b C_{e}},
\end{aligned}
$$

where KF is the Freundlich sorption coefficient, $n$ is an empirical coefficient indicative of the intensity of adsorption, $q_{\max }$ is the maximum adsorption capacity $(\mathrm{mg} / \mathrm{g})$, and $b$ is the adsorption intensity $(\mathrm{L} / \mathrm{mg})$.

3.2. Continuous Measurements. As described previously, the aim of the continuous tests is to find the propagation of $\mathrm{Pb}^{+2}$ and $\mathrm{Ni}^{+2}$ plume through Iraqi sandy soil aquifer with presence of WFS as LPB or WFS + FS as PRB. The mathematical modeling for this situation requires solving the following equations.

Two-dimensional groundwater flow equation for steadystate condition [43]:

$$
\frac{\partial}{\partial x}\left(K_{x} \frac{\partial h}{\partial x}\right)+\frac{\partial}{\partial y}\left(K_{x y} \frac{\partial h}{\partial y}\right)=0,
$$

where $K$ is the hydraulic conductivity coefficient $(\mathrm{cm} / \mathrm{s})$.

Two-dimensional solute transport equation for transient state condition [43]:

$$
D_{x} \frac{\partial^{2} C}{\partial x^{2}}+D_{y} \frac{\partial^{2} C}{\partial y^{2}}-V_{x} \frac{\partial C}{\partial x}=R \frac{\partial C}{\partial t},
$$

where $R$ is the retardation factor, $D$ is the dispersion coefficient $\left(\mathrm{cm}^{2} / \mathrm{s}\right)$, and $V$ is the flow velocity $(\mathrm{cm} / \mathrm{s})$.

Isotherm model (either Freundlich or Langmuir isotherm) was used to describe the reaction occurring through the migration of contaminant which incorporates with retardation factor. This system of equations is solved numerically by finite element method using computer solution (COMSOL) Multiphysics 3.5a (2008) program.

\section{Results and Discussion}

4.1. Batch Operating Conditions. The variation of $\mathrm{Pb}^{+2}$ and $\mathrm{Ni}^{+2}$ removal efficiencies due to change of contact time $(\leq 180 \mathrm{~min})$ and initial $\mathrm{pH}(3-7)$ for WFS dosage of $2.5 \mathrm{~g}$ per $100 \mathrm{~mL}$ of aqueous solution is plotted in Figures 2(a) and 2(b). These figures signified that the contact time has significant role in the removal process and the sorption rate increased dramatically in the initial periods of time until it stabilized beyond $60 \mathrm{~min}$. This behavior may be related with number of binding sites which is expected to be high in the initial stages and then decrease. It is obvious that the equilibrium time can be taken as 60 where efficiency exceeded $95 \%$ for the two metals under consideration.

Also, Figure 2 elucidates the influence of initial $\mathrm{pH}$ on the sorption of $\mathrm{Pb}^{+2}$ and $\mathrm{Ni}^{+2}$ onto WFS material and the results proved that the maximum sorption efficiency for these metals occurred at $\mathrm{pH}$ equal to 4 and 6 , respectively. The decrease or increase in the value of $\mathrm{pH}$ around the mentioned best values will cause a clear decrease in the efficiency; for example, the sorption efficiencies of $\mathrm{Pb}^{+2}$ and $\mathrm{Ni}^{+2}$ for contact time of 60 min may decrease from 97 to $95 \%$ at $\mathrm{pH}$ of 4 and 6 to become 70 and $66 \%$, respectively, when $\mathrm{pH}$ is equal to 3. Competition between metals ions and protons may be the main reason for this behavior; however, the same reduction can be recognized for increasing of $\mathrm{pH}$ to be 7 and this may be to generate repulsive forces between metal ions and surface of the sorbent [44]. For the same operational conditions, the measurements certified that the 


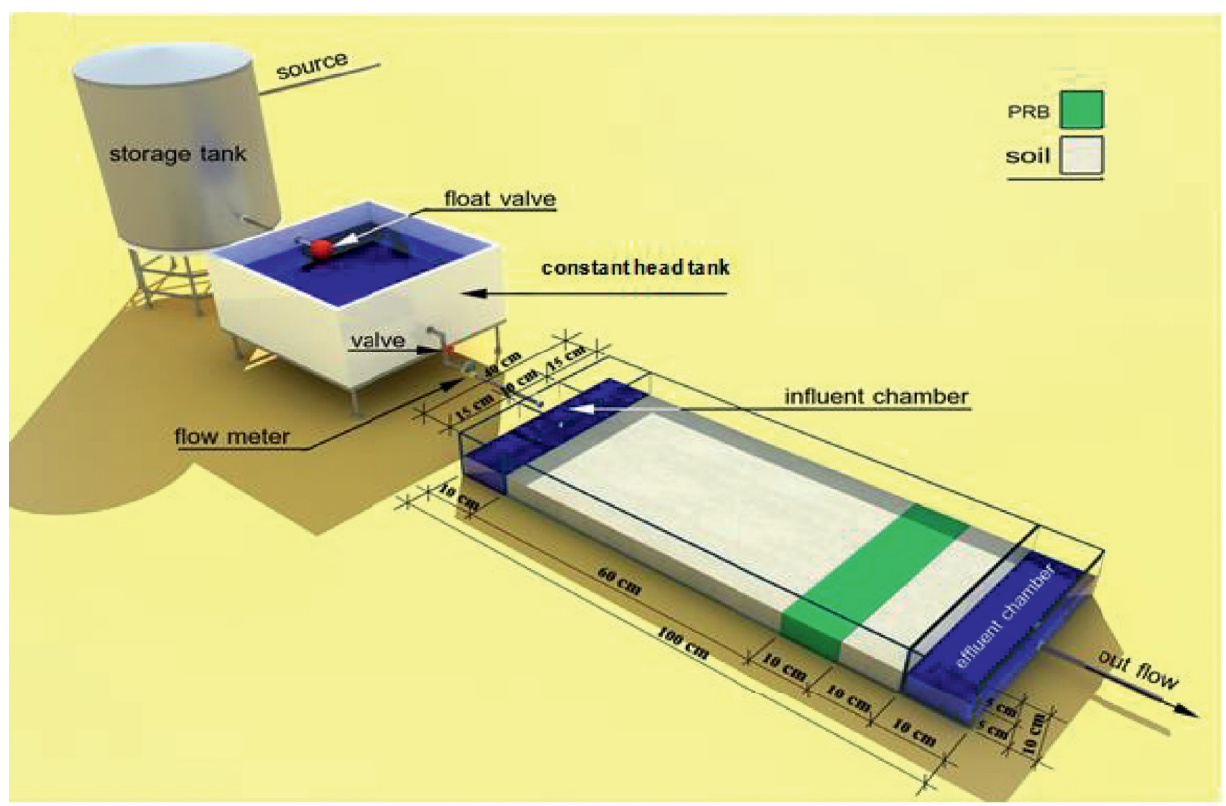

(a)

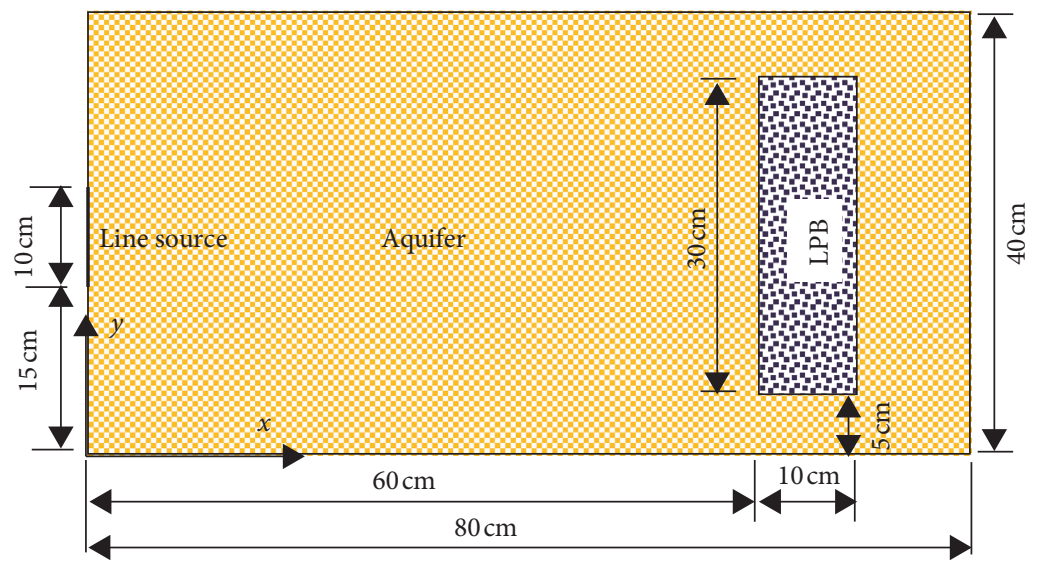

(b)

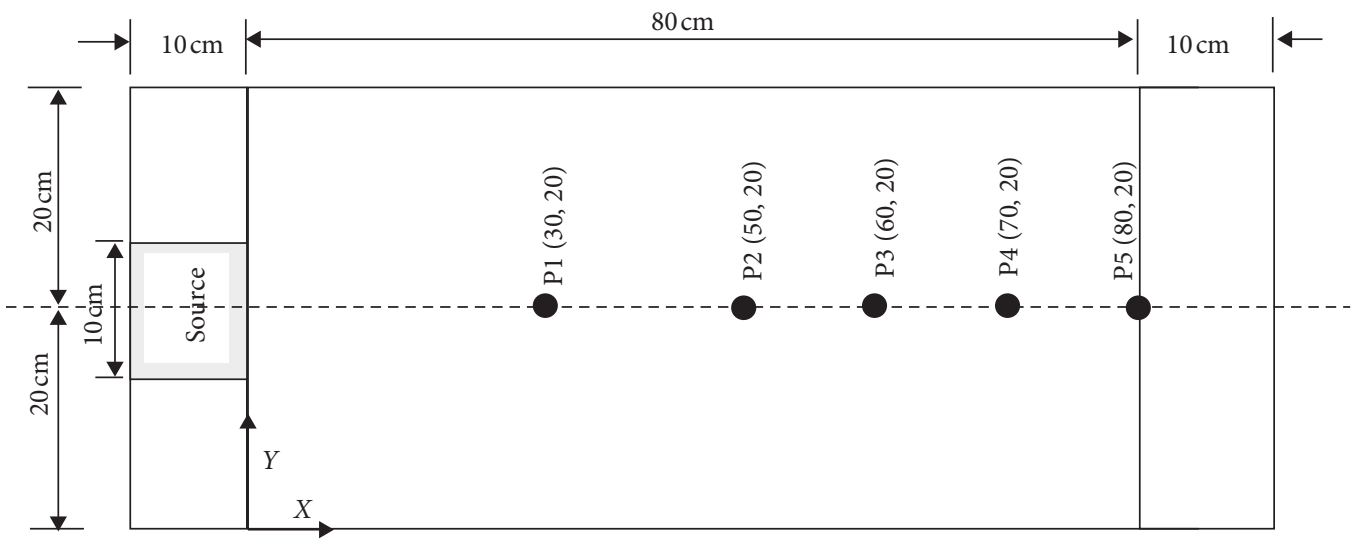

(c)

FIgURE 1: Schematic diagram for all components of the two-dimensional bench-scale experimental set-up.

removal efficiency of $\mathrm{Pb}^{+2}$ onto WFS is greater than that of $\mathrm{Ni}^{+2}$ because the lead ions have high infinity towards adopted sorbent in comparison with nickel ions.
Figure 3(a) shows the dependence of $\mathrm{Pb}^{+2}$ and $\mathrm{Ni}^{+2}$ sorption on the quantity of WFS added to $100 \mathrm{~mL}$ of solution where it seems that the removal efficiencies for these metals 


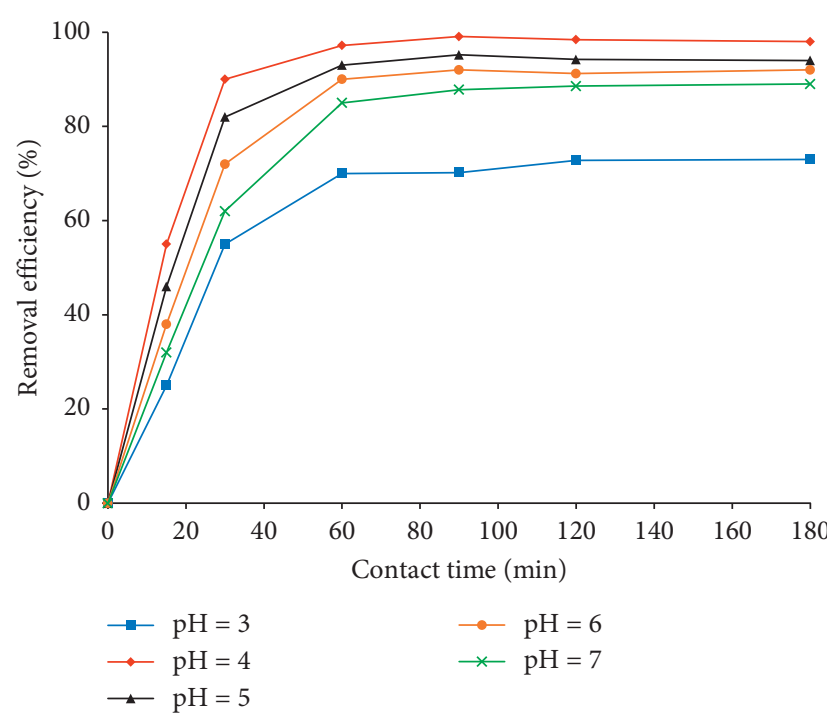

(a)

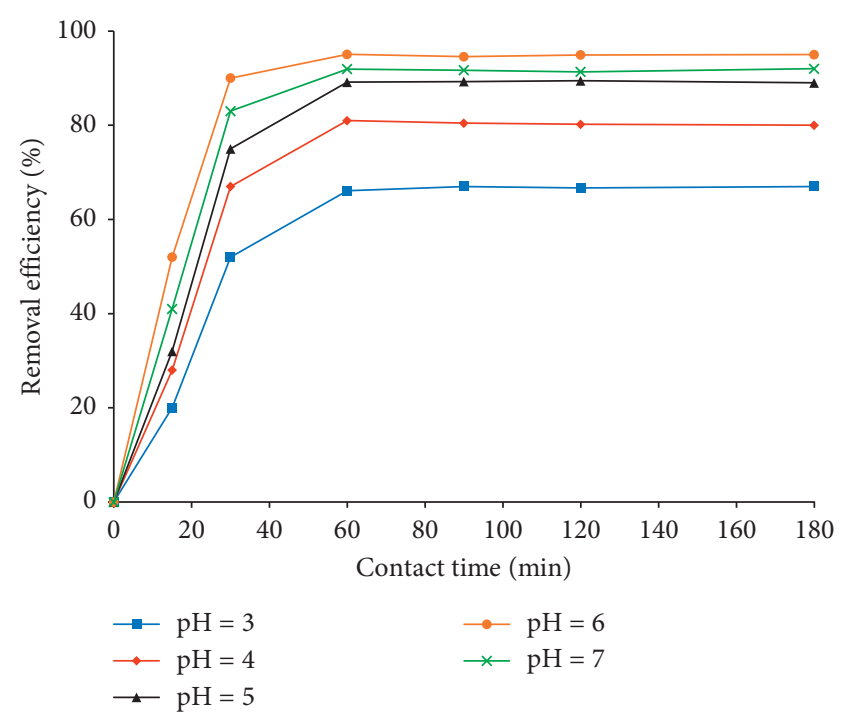

(b)

FIgURe 2: Removal efficiencies of $\mathrm{Pb}^{+2}$ and $\mathrm{Ni}^{+2}$ ions onto WFS at different values of contact time and initial $\mathrm{pH}$. (a) Lead $($ dosage $=2.5 \mathrm{~g} /$ $100 \mathrm{~mL}, C_{\mathrm{o}}=50 \mathrm{mg} / \mathrm{L}$, and speed $\left.=250 \mathrm{rpm}\right)$. (b) Nickel (dosage $=2.5 \mathrm{~g} / 100 \mathrm{~mL}, C_{\mathrm{o}}=50 \mathrm{mg} / \mathrm{L}$, and speed $\left.=250 \mathrm{rpm}\right)$.

are equal to 55 and $48 \%$ for $0.5 \mathrm{~g}$ dosage. However, an improvement in these efficiencies was recorded to exceed the 95\% when the dosage became $2.5 \mathrm{~g}$ and removal process nearly stabilized beyond this value until the $4 \mathrm{~g}$. The increase of sorbent material will increase the vacant sites prepared for capturing of metal ions; so, this will definitely improve the sorption as described previously. In addition, the increase of initial metal concentration for certain amount of WFS can cause an obvious reduction in the removal percentage as plotted in Figure 3(b) and this behavior is considered logical because of the increase of metal ions for the same number of binding sites. It seems that the increase of metal concentration from 50 to $250 \mathrm{mg} / \mathrm{L}$ will be associated with decrease of efficiency from $\geq 95 \%$ to 85.4 and $47.2 \%$ for lead and nickel ions, respectively; however, this huge difference in removal efficiencies may be attributed to difference in affinity of adopted metals towards the WFS sorbent. Finally, Figure 3(c) plots the influence of agitation speed on the sorption of $\mathrm{Pb}^{+2}$ and $\mathrm{Ni}^{+2}$ from aqueous solution. Although sorbent has the ability to remove metal ions from solution (efficiency ranged from 47 to $56 \%$ ) without agitation (i.e., speed $=$ zero), agitation speed must be applied in the batch tests. This speed will accelerate the removal process through achieving the required contact between solid particles and metal ions where the removal exceeded $95 \%$ at speed equal to $250 \mathrm{rpm}$.

4.2. Sorption Isotherms. The sorption data for interaction of $\mathrm{Pb}^{+2}$ and $\mathrm{Ni}^{+2}$ ions with WFS at best operational condition specified from previous step (Section 4.1) were fitted with Langmuir and Freundlich models to determine their constants. Linearization for these models was adopted to calculate the slope and intercept of each model; however, all constants are inserted in Table 2. Based on the values of determination coefficient $\left(R^{2}\right)$, Langmuir model is more representative for the sorption data from Freundlich isotherm as shown in Figure $3(\mathrm{~d})$ where $R^{2}>0.99$. Results proved that the maximum sorption capacity $\left(q_{\max }\right)$ of WFS for $\mathrm{Pb}^{+2}$ is threefold that for $\mathrm{Ni}^{+2}$ with values equal to 13.966 and $4.227 \mathrm{mg} / \mathrm{g}$, respectively. In comparison with previous studies, the values of sorption capacity measured in this work are less than the values achieved by traditional sorbents like activated carbon and zeolite; however, high cost of these sorbents forms beneficial parameter to use nonexpensive WFS by-product. Also, the affinity constant $(b)$ for $\mathrm{Pb}^{+2}$ $(=0.647 \mathrm{~L} / \mathrm{mg})$ seems greater than that of $\mathrm{Ni}^{+2}(0.099 \mathrm{~L} / \mathrm{mg})$ and this result is consistent with outputs of batch tests about the affinity of adopted metal ions towards WFS described previously. Accordingly, Langmuir model was incorporated with (5) that described the solute transport in the subsurface environment to represent the reaction term corresponding to the "sorption" process.

4.3. Fourier Transform Infrared (FT-IR) Analysis. This analysis was achieved using FT-IR spectrophotometer 8000 , Shimadzu, with wavenumber ranging from 400 to $4000 \mathrm{~cm}^{-1}$ to identify the functional groups that have ability to enhance the sorption process. The FT-IR spectra for WFS were also measured before interaction in our previous studies [44, 45]. Figure 4 elucidates the FT-IR spectra for interaction of WFS with $\mathrm{Pb}^{+2}$ and $\mathrm{Ni}^{+2}$; however, this figure in combination with Table 3 certified that the bands of the groups $\mathrm{O}-\mathrm{H}, \mathrm{H}-\mathrm{O}-\mathrm{H}$, $\mathrm{C}-\mathrm{O}, \mathrm{O}-\mathrm{Si}-\mathrm{O}$, and $\mathrm{Si}-\mathrm{O}$ were responsible of the sorption process [46-48].

Generally, two mechanisms for adsorption of heavy metals can be recognized; (i) specific adsorption, which is characterized by more selective and less reversible reactions including chemisorbed inner-sphere complexes, and (ii) nonspecific adsorption (or ion exchange), which involves rather weak and less selective outer-sphere complexes. 


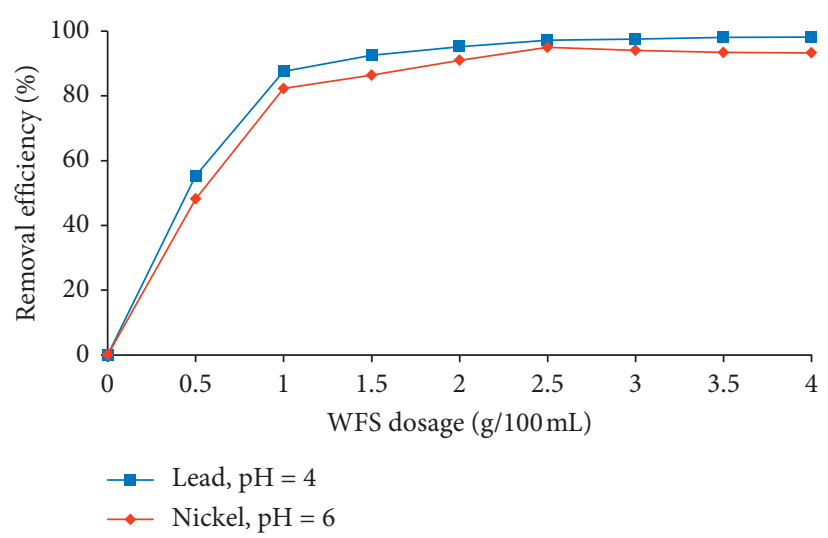

(a)

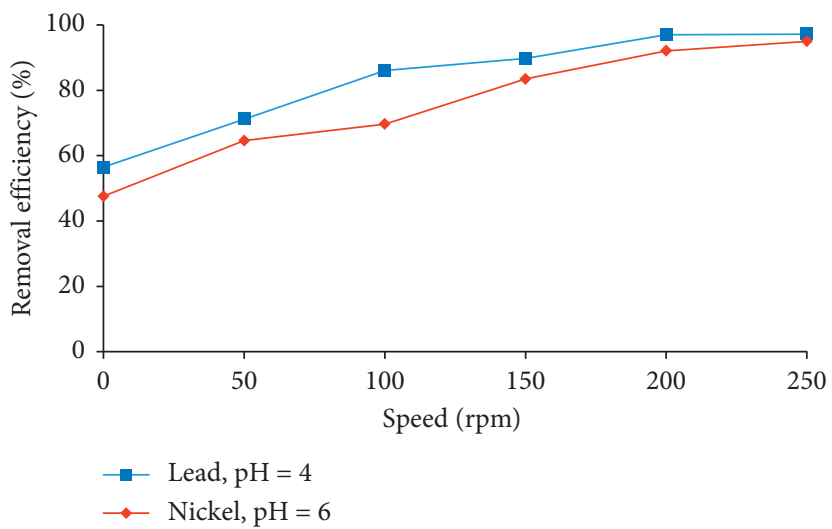

(c)

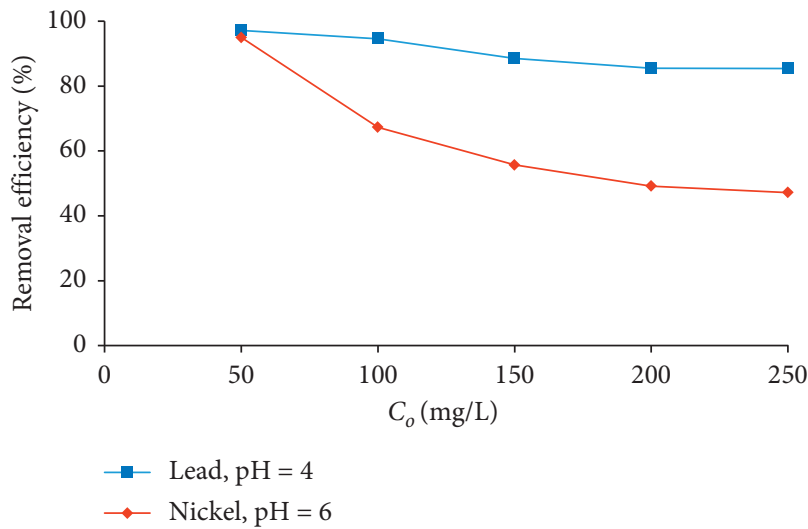

(b)

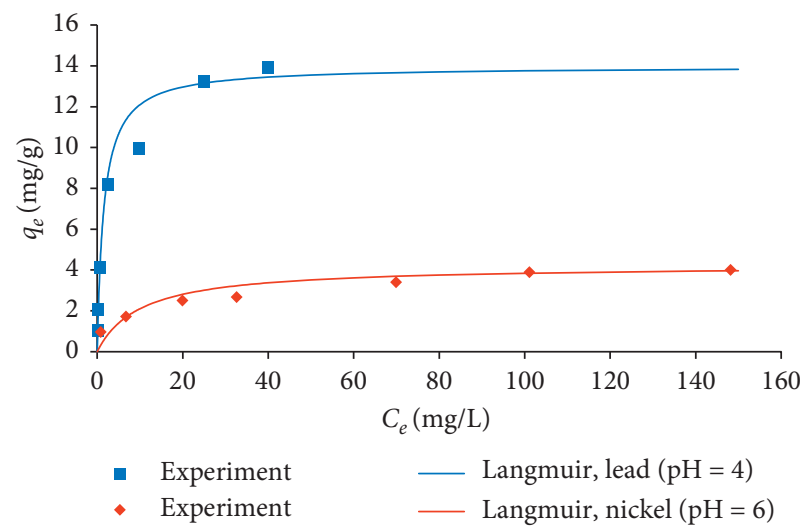

(d)

Figure 3: Removal efficiencies of $\mathrm{Pb}^{+2}$ and $\mathrm{Ni}^{+2}$ ions onto WFS at different values of (a) sorbent dosage, (b) initial concentration, and (c) agitation speed as well as (d) Langmuir isotherm model for sorption data.

TABLE 2: Constants of isotherm models with statistical measures for sorption of $\mathrm{Pb}^{+2}$ and $\mathrm{Ni}^{+2}$ ions onto WFS (time $=60 \mathrm{~min}, \mathrm{pH}=4$ $\left(\mathrm{Pb}^{+2}\right)$ and $6\left(\mathrm{Ni}^{+2}\right)$, dosage $=2.5 \mathrm{~g} / 100 \mathrm{~mL}$, and agitation speed $=250 \mathrm{rpm}$ ).

\begin{tabular}{lccc}
\hline \multirow{2}{*}{ Isotherm model } & Parameter & \multicolumn{2}{c}{ Value } \\
& & $\mathrm{Pb}^{+2}$ & $\mathrm{Ni}^{+2}$ \\
\hline \multirow{3}{*}{ Freundlich } & $K_{F}(\mathrm{mg} / \mathrm{g})(\mathrm{L} / \mathrm{mg})^{1 / n}$ & 4.248 & 1.023 \\
& $1 / n$ & 0.537 & 0.288 \\
& $R^{2}$ & 0.9276 & 0.9846 \\
Langmuir & $b(\mathrm{~L} / \mathrm{mg})$ & 0.647 & 0.099 \\
& $q_{\max }(\mathrm{mg} / \mathrm{g})$ & 13.966 & 4.227 \\
& $R^{2}$ & 0.9983 & 0.9916 \\
\hline
\end{tabular}

Specific adsorption occurs slowly and brings about strong and irreversible binding of heavy metal ions with adsorbent [49]. Meanwhile, cation exchange is a form of outer-sphere complexation with only weak covalent bonding between metals and charged adsorbent surfaces. It is reversible and occurs rather quickly because the reactions are governed by diffusion and are of electrostatic nature $[50,51]$. The WFS contains different functional groups mentioned previously; therefore, the predominant mechanism can be explained based on the following:
(1) There are interactions between the functional groups on the surface of the WFS and heavy metals especially with $-\mathrm{OH}$

(2) Another possibility is that heavy metals could be retained through ions exchanges on the surface [52]

(3) Silica oxide also may participate in the complexing and precipitation process of heavy metals onto surface $[51,53]$ as illustrated in the following reaction:

$$
2(\equiv \equiv \mathrm{SiOH})+M^{+2} \longrightarrow \equiv \equiv(\mathrm{SiO})_{2} M+2 H^{+},
$$

where $M$ is lead or nickel ion.

\subsection{Continuous Mode}

4.4.1. Longitudinal Dispersion Coefficient. It is obvious that the solution of (5) requires specifying the values of dispersion coefficients (i.e., $D_{x}$ and $D_{y}$ ). In this study, the longitudinal dispersion coefficient $\left(D_{L}\right.$ or $\left.D_{x}\right)$ is measured by tracer experiments as described in Section 2.3. Measurements lead to producing a set of data related between the pore water velocity and DL for WFS and Iraqi sandy soil; however, the data of each medium are fitted with linear 


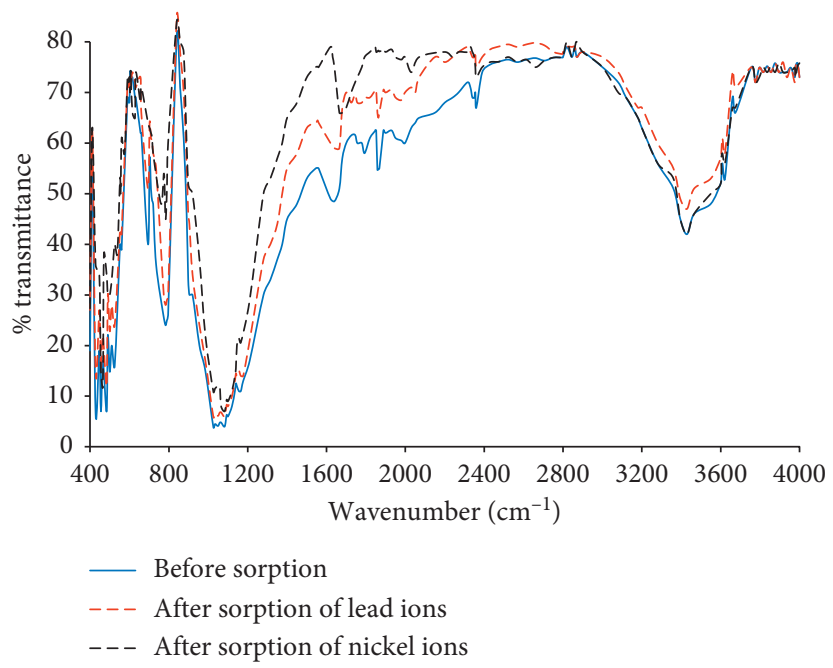

FIGURE 4: FT-IR analysis of WFS before (reproduced with permission from [44]) and after removal of $\mathrm{Pb}^{+2}$ and $\mathrm{Ni}^{+2}$ ions from aqueous solution.

TABLE 3: Functional groups responsible for $\mathrm{Pb}^{+2}$ and $\mathrm{Ni}^{+2}$ sorption onto WFS.

\begin{tabular}{lcc}
\hline Metal & Wavenumber $\left(\mathrm{cm}^{-1}\right)$ & Functional group \\
\hline & 3619 & O-H band \\
Lead & 1668 & H-O-H \\
& 1100 & C-O \\
& 662 & O-Si-O \\
& 522 & Si-O band \\
Nickel & 3654 & O-H band \\
& 1613 & H-O-H \\
& 1123 & C-O and O-H band \\
& 681 & O-Si-O \\
\hline
\end{tabular}

relationship and its slope represents the longitudinal dispersivity $\left(\alpha_{L}\right)$. This term is required in the determining of DL and, consequently, the solving of solute transport equation using COMSOL software. The values of $\alpha L$ are equal to 0.753 and $0.701 \mathrm{~m}$ for WFS and Iraqi sandy soil, respectively. The transverse dispersion coefficient $\left(D_{T}\right.$ or $\left.D_{y}\right)$ for beds under consideration are taken equal to 10 percent of the longitudinal dispersion coefficient according to previous studies [43] because (5) simulates the unidirectional flow in the $x$-direction.

4.4.2. Metal Transport through Aquifer and LPB. Propagation of $\mathrm{Pb}^{+2}$ and $\mathrm{Ni}^{+2}$ ions in the experimental packed tank illustrated in Figure 1(b) was monitored at locations P4 and P5. The selection of these two locations is related with the main objective of LPB which is to protect the region beyond the barrier. Figures $5(\mathrm{a})$ and $5(\mathrm{~b})$ plot the normalized concentrations $\left(C / C_{\mathrm{o}}\right)$ of $\mathrm{Pb}^{+2}$ and $\mathrm{Ni}^{+2}$ at mentioned locations and it is clear that LPB has high ability in the protection of the locations situated at the downgradient side especially adjacent to the barrier. For example, the time required to make $C / C_{\mathrm{o}}$ reach the breakthrough point $(=5 \%)$ at $\mathrm{P} 4$ (which is immediately beyond the $\mathrm{LPB}$ ) is more than fivefold the time for P5 (which is situated at $10 \mathrm{~cm}$ after P4). Also, it seems that there is a big difference between the $C / C_{\mathrm{o}}$ of lead and nickel for the same port beyond WFSLPB where this ratio at P4 after 15 days is equal to 0.00175 and 0.469 for the two metals, respectively. This difference may be attributed to high affinity of lead ions towards the WFS in comparison with affinity of nickel ions.

The experimental measurements are simulated by solving the groundwater flow (as in (4)) and solute transport (as in (5)) simultaneously using COMSOL program. The solution procedure firstly depended on the solving of (4) for nonuniform steady-state flow and, then, its outputs will be the input for (5). The solution of the last equation will plot the temporal and spatial variation of contaminant concentrations. For implementation of solution, all information related with characteristics of Iraq sandy soil and WFS like porosity, hydraulic conductivity, and dispersivity as well as bulk density with the geometry of the physical model is mentioned previously. Zero concentration at time equal to zero was adopted as initial boundary; however, concentration and hydraulic head are substituted as $50 \mathrm{mg} / \mathrm{L}$ and $0.1 \mathrm{~m}$, respectively, for boundary conditions at line source. These conditions are taken of advective flux for concentration and zero head for water at right hand side of Figure 1(b) while no flux/symmetry can be applied for remaining exterior boundaries.

Figures 5(a) and 5(b) present the $C / C_{\mathrm{o}}$ calculated from COMSOL software in comparison with experimental measurements for locations P4 and P5. It is obvious that there is satisfactory matching between measurements and model predictions with Nash-Sutcliffe efficiency greater than 0.95 , so the verified model can be used extensively in the plotting of the velocity field and concentration distribution within the adopted physical model as shown in Figures 5(c) and 6. The arrows of velocity certify that the water path in the flow domain is deviated around the LPB and two stagnant points can be observed adjacent to the barrier in the up- and down-gradient sides as plotted in Figure 5(c). Also, the propagation of $\mathrm{Pb}^{+2}$ and $\mathrm{Ni}^{+2}$ fronts 


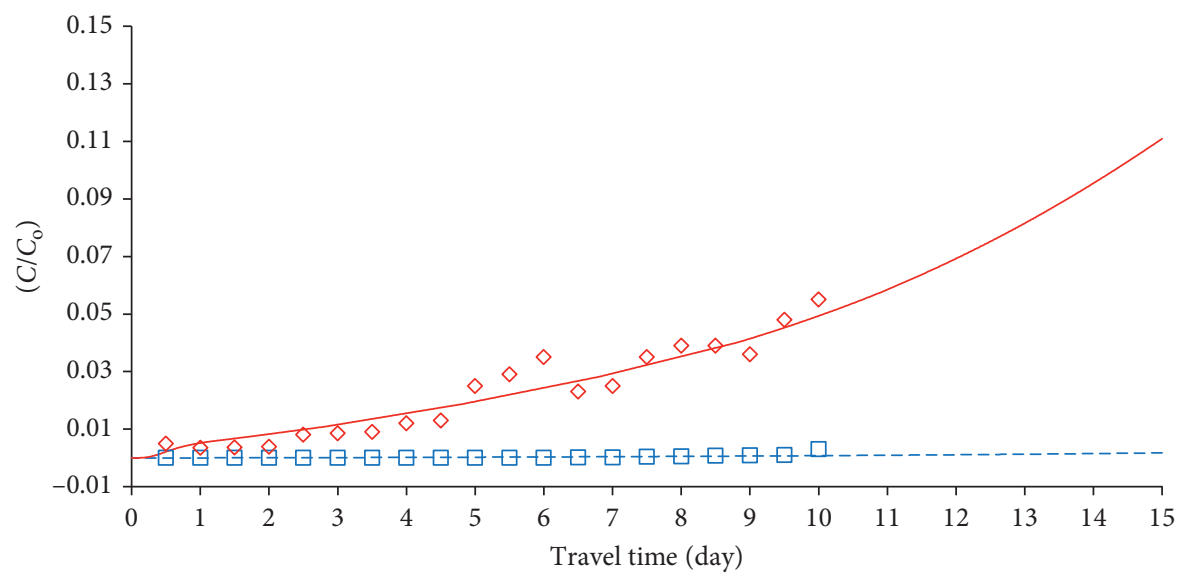

- - COMSOL (P4)

— COMSOL (P5)

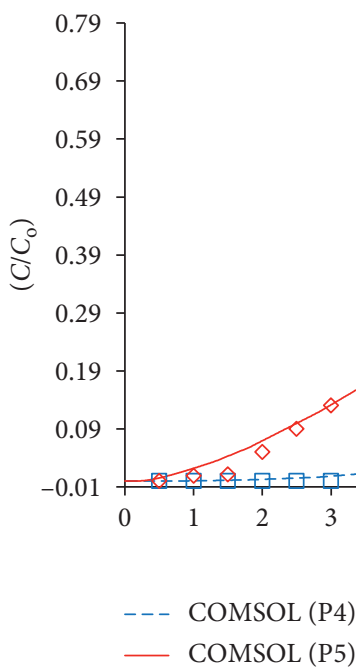

$\square \quad$ Experiment (P4)

$\diamond \quad$ Experiment (P5)

(a)

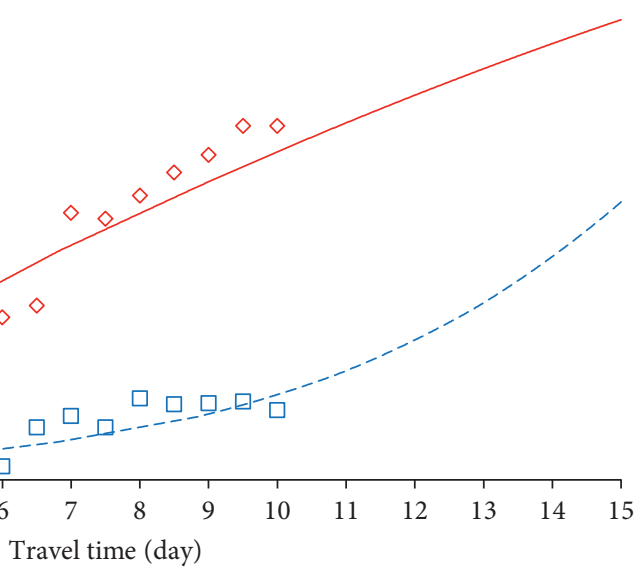

$$
\square \text { Experiment (P4) }
$$$$
\diamond \text { Experiment (P5) }
$$

(b)

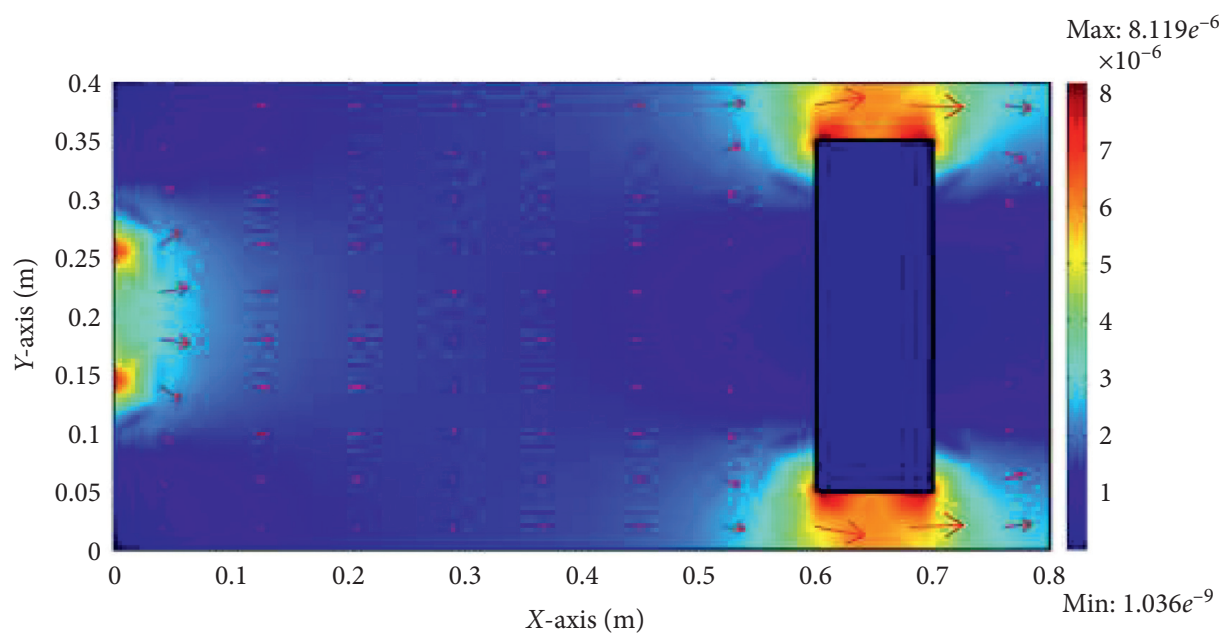

(c)

FIGURE 5: Comparison between COMSOL solution and experimental results for (a) $\mathrm{Pb}^{+2}$ and (b) $\mathrm{Ni}^{+2}$ normalized concentrations in the presence of WFS as LPB for distribution of (c) velocity field. 


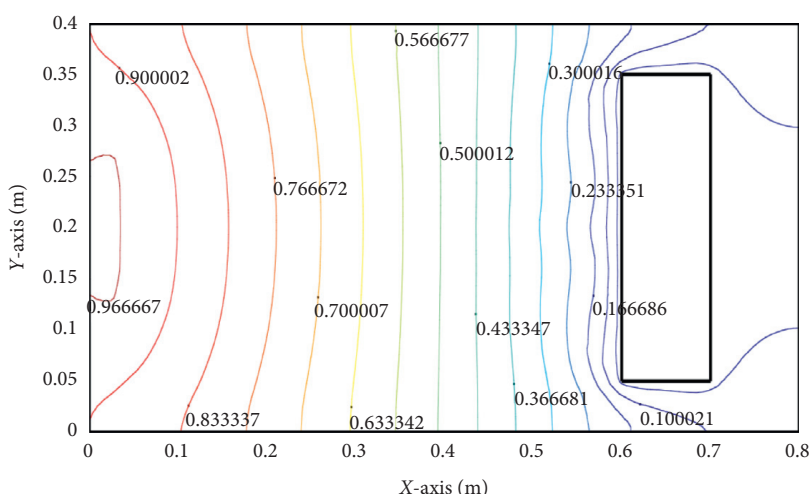

(a)

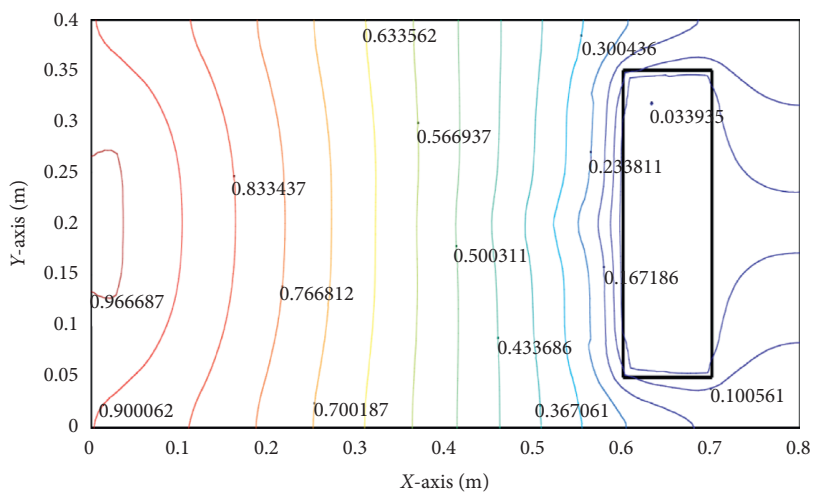

(c)

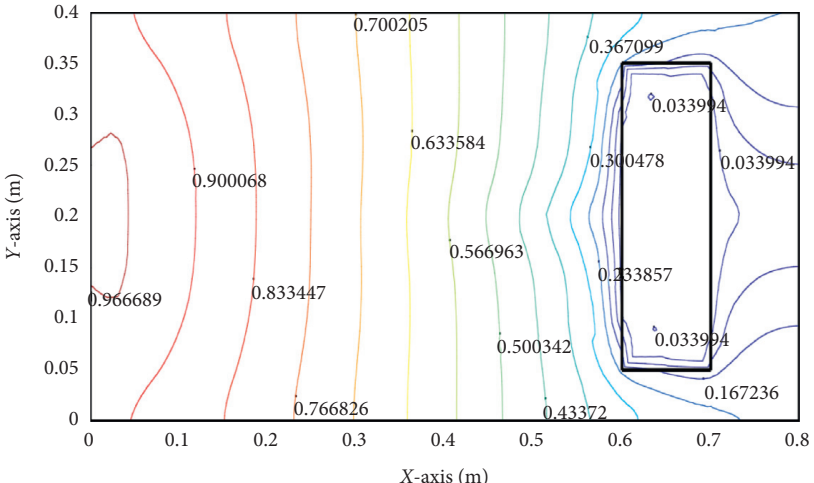

(b)

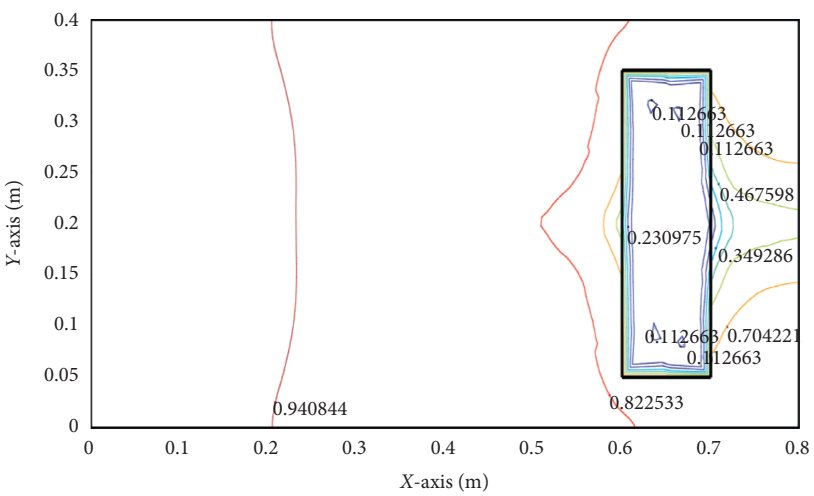

(d)

FIGURE 6: Normalized concentration contours of lead and nickel ions across the 2D sandy soil packed tank in the presence of WFS-LPB as predicted by the COMSOL software at different values of travel time. (a) Time = 1 day; contour: normalized concentration of lead ions. (b) Time $=10$ days; contour: normalized concentration of lead ions. (c) Time $=1$ day; contour: normalized concentration of nickel ions. $(\mathrm{d})$ Time $=10$ days; contour: normalized concentration of nickel ions.

through the packed bed can be plotted in Figure 6 and it seems that the LPB plays a significant role in the retardation of advective transport for contaminant especially directly beyond the barrier for time equal to 1 and 10 days after the beginning of transportation process.

4.4.3. Metal Transport through Aquifer and PRB. Monitoring of normalized concentrations for $\mathrm{Pb}^{+2}$ and $\mathrm{Ni}^{+2}$ fronts at ports $\mathrm{P} 1$ to $\mathrm{P} 4$ was implemented for two-dimensional tank packed with Iraqi sandy soil in the presence of WFS-FS PRB. Figures 7(a) and 7(d) show the breakthrough curves at these ports for the two metals when the thickness of the barrier is equal to $10 \mathrm{~cm}$ and applied flow rate is $100 \mathrm{~mL} / \mathrm{min}$. It seems that the concentrations of the two metals are decreased far from the line source towards the PRB due to longitudinal and transverse dispersion. This figure illustrates that the barrier is able to decrease the concentration of pollutant at its downgradient side with capturing efficiency for lead ions exceeding that for nickel ions. In addition, the breakthrough time (which means the time required to maintain the normalized concentration of the contaminant beyond the barrier within the environmental acceptable limit or $\leq 5 \%$ and this time represents the longevity of the barrier) is equal to 83 and $9 \mathrm{hrs}$ as listed in Table 4 for $\mathrm{Pb}^{+2}$ and $\mathrm{Ni}^{+2}$, respectively, at port $\mathrm{P} 4$ with coordinates of $0.7 \mathrm{~m} \times 0.2 \mathrm{~m}$.
Also, COMSOL software was applied to simulate the experimental results through the solving of the solute transport equation (5) in combination with Langmuir model. The unidirectional flow of water in the $x$-direction only can be assumed in the representation of contaminant transport equation and this assumption is consistent with a previous study [54]. The solution process requires inputting the dimensions of the flow domain with characteristics of the Iraqi soil and WFS-FS barrier in conjugation with initial and boundary condition; however, these data are mentioned previously. Figures 7 (a) and 7 (d) present a comparison between the model predictions and experimental results beyond PRB of $10 \mathrm{~cm}$ thickness for adopted metals. A good concurrence between predictions and measurements can be recognized where Nash-Sutcliffe efficiency for all ports in this figure exceeded the value of 0.85 ; and, accordingly, the verified model can be used to study the effect of increment in the barrier thickness on its longevity. Two values of barrier thickness $(20$ and $30 \mathrm{~cm}$ ) were substituted in the verified model and variation of breakthrough curves at ports P1 to P4 can be plotted in Figures $7(\mathrm{~b})$ and $7(\mathrm{c})$ for $\mathrm{Pb}^{+2}$ and Figures $7(\mathrm{e})$ and $7(\mathrm{f})$ for $\mathrm{Ni}^{+2}$. The predictions elucidated that the thicker barrier is more reliable in the elimination of contamination with high increase in the longevity as explained in Table 4. The predictions of $C / C_{\mathrm{o}}$ for $\mathrm{Pb}^{+2}$ when thickness of the barrier is equal to $30 \mathrm{~cm}$ (Figure $7(\mathrm{~d})$ ) at port 


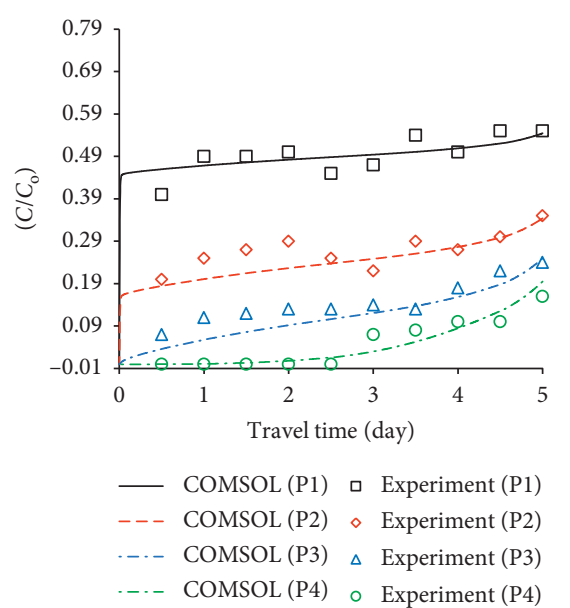

(a)

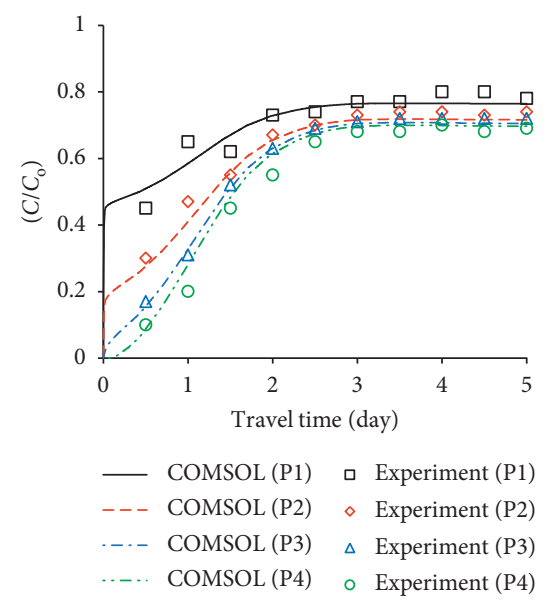

(d)

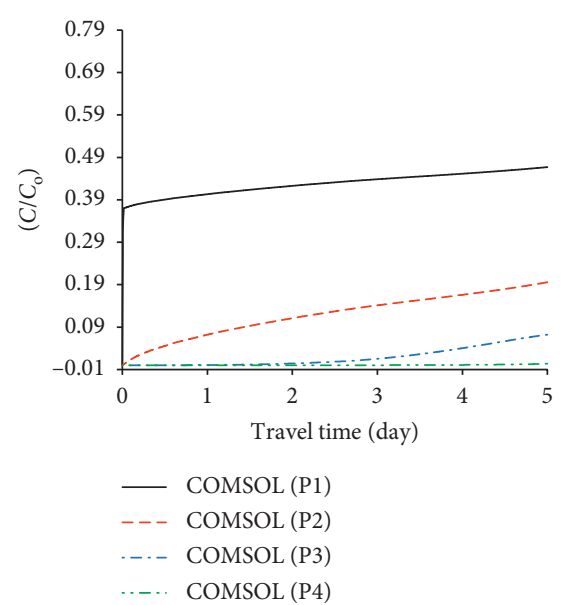

(b)

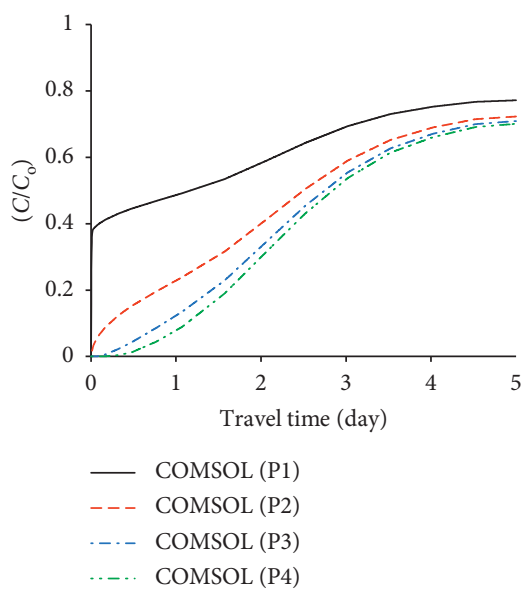

(e)

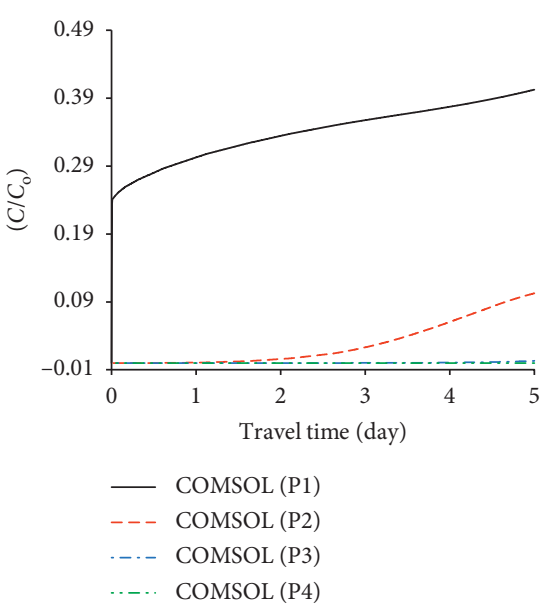

(c)

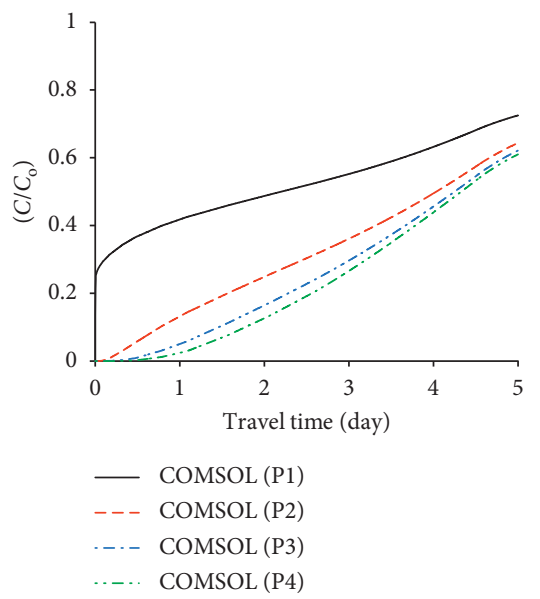

(f)

FIgURE 7: Measured and predicted breakthrough curves for $\mathrm{Pb}^{+2}$ and $\mathrm{Ni}^{+2}$ at selected locations in the sandy soil with presence of WFS-FS as PRB for flow rate of $100 \mathrm{~mL} / \mathrm{min}$. (a) PRB $(10 \mathrm{~cm}$, WFS + FS, lead $(\mathrm{pH}=4))$. (b) PRB $(20 \mathrm{~cm}, \mathrm{WFS}+\mathrm{FS}, \mathrm{lead}(\mathrm{pH}=4))$. (c) PRB $(30 \mathrm{~cm}$, $\mathrm{WFS}+\mathrm{FS}$, lead $(\mathrm{pH}=4))$. (d) PRB $(10 \mathrm{~cm}, \mathrm{WFS}+\mathrm{FS}$, nickel $(\mathrm{pH}=4))$. (e) PRB $(20 \mathrm{~cm}, \mathrm{WFS}+\mathrm{FS}$, nickel $(\mathrm{pH}=4))$. (f) PRB $(30 \mathrm{~cm}$, $\mathrm{WFS}+\mathrm{FS}$, nickel $(\mathrm{pH}=4))$.

TABLE 4: Longevities of WFS-FS barriers under the variation of thickness for capturing of $\mathrm{Pb}^{+2}$ and $\mathrm{Ni}^{+2}$ ions.

\begin{tabular}{lcc}
\hline \multirow{2}{*}{ Thickness of WFS-FS PRB (m) } & \multicolumn{2}{c}{ Longevity (hrs) } \\
& $\mathrm{Pb}^{+2}$ & $\mathrm{Ni}^{+2}$ \\
\hline 0.1 & 83 & 9 \\
0.2 & --- & 19.4 \\
0.3 & --- & 31.3 \\
\hline
\end{tabular}

----: run time equal to $120 \mathrm{hrs}$.

P4 $(0.7 \mathrm{~m}, 0.2 \mathrm{~m})$ have not been inserted because the values of $C / C_{\mathrm{o}}$ at port P3 $(0.6 \mathrm{~m}, 0.2 \mathrm{~m})$ are approximately equal to zero; so, it is expected that these values also are equal zero for $\mathrm{P} 4$ which is situated at $0.1 \mathrm{~m}$ beyond P3.

\section{Conclusions}

The waste foundry sand by-product could be reused effectively in the capturing of the $\mathrm{Pb}^{+2}$ and $\mathrm{Ni}^{+2}$ ions from contaminated aqueous solutions; so, it might be applied in
LPB and PRB for protection of water resources. The maximum removal efficiencies in batch study exceeded 95\% at contact time, WFS dosage, initial $\mathrm{pH}$, and agitation speed equal to $60 \mathrm{~min}, 0.25 \mathrm{~g} / 100 \mathrm{~mL}, 4$ for $\mathrm{Pb}^{+2}$ and 6 for $\mathrm{Ni}^{+2}$, $250 \mathrm{rpm}$, respectively, for initial concentration of $50 \mathrm{mg} / \mathrm{L}$. Sorption data were represented by Langmuir isotherm model and this means that the chemical sorption would be the predominant mechanism in the removal process enhanced by O-H, H-O-H, C-O, O-Si-O, and Si-O functional groups. Results elucidated that the maximum adsorption capacity and affinity of lead ions onto WFS are greater than those of nickel ions. Pure WFS with low hydraulic conductivity $\left(=3.8 \times 10^{-7} \mathrm{~cm} / \mathrm{s}\right)$ was utilized as LPB between the contamination source and locations that must be protected; however, this barrier plays a potential role in the redirection of the contaminant advective front far away from these locations. PRB consisting of $18 \%$ WFS and $82 \%$ filter sand mixture was able to capture $\mathrm{Pb}^{+2}$ and $\mathrm{Ni}^{+2}$ ions while the longevity of barrier increased directly with increase of its thickness. Finally, COMSOL Multiphysics 3.5a had a good 
ability in the simulation of normalized concentrations for breakthrough curves of the two metals for aquifer with presence of LPB and PRB.

\section{Data Availability}

No data were used to support this study.

\section{Conflicts of Interest}

The authors declare that they have no conflicts of interest.

\section{Acknowledgments}

The authors would like to gratefully acknowledge the technical support for Laith A. Naji, Technical Instructors Training Institute, Middle Technical University, Baghdad, Iraq. Mu. Naushad is grateful to the Researchers Supporting Project number (RSP-2020/8), King Saud University, Riyadh, Saudi Arabia, for the financial support.

\section{References}

[1] J. Bear, Dynamics of Fluids in Porous Media, Elsevier, New York, NY, USA, 1979.

[2] M. Naushad, A. Mittal, M. Rathore, and V. Gupta, "Ionexchange kinetic studies for Cd (II), Co (II), Cu (II), and $\mathrm{Pb}$ (II) metal ions over a composite cation exchanger," Desalination and Water Treatment, vol. 54, no. 10, pp. 2883-2890, 2015.

[3] M. Naushad and Z. A. ALOthman, "Separation of toxic $\mathrm{Pb}^{2+}$ metal from aqueous solution using strongly acidic cationexchange resin: analytical applications for the removal of metal ions from pharmaceutical formulation," Desalination and Water Treatment, vol. 53, no. 8, pp. 2158-2166, 2015.

[4] G. Sharma and M. Naushad, "Adsorptive removal of noxious cadmium ions from aqueous medium using activated carbon/ zirconium oxide composite: isotherm and kinetic modelling," Journal of Molecular Liquids, vol. 310, Article ID 113025, 2020.

[5] N. S. Shah, J. A. Khan, M. Sayed et al., "Synergistic effects of $\mathrm{H} 2 \mathrm{O} 2$ and $\mathrm{S} 2 \mathrm{O} 82-$ in the gamma radiation induced degradation of Congo-red dye: kinetics and toxicities evaluation," Separation and Purification Technology, vol. 233, Article ID 115966, 2020.

[6] P. L. Hall and H. Quam, "Countermeasures to control oil spills in Western Canadaa," Ground Water, vol. 14, no. 3, pp. 163-169, 1976.

[7] T. Anitha, P. Senthil Kumar, and K. Sathish Kumar, "Synthesis of nano-sized chitosan blended polyvinyl alcohol for the removal of Eosin Yellow dye from aqueous solution," Journal of Water Process Engineering, vol. 13, pp. 127-136, 2016.

[8] M. Cempel and G. Nikel, "Nickel: a review of its sources and environmental toxicology," Polish Journal of Environmental Studies, vol. 15, no. 3, pp. 375-382, 2006.

[9] B. Debnath, W. S. Singh, and K. Manna, "Sources and toxicological effects of lead on human health," Indian Journal of Medical Specialities, vol. 10, no. 2, pp. 66-71, 2019.

[10] M. Naushad, "Surfactant assisted nano-composite cation exchanger: development, characterization and applications for the removal of toxic $\mathrm{Pb}^{2+}$ from aqueous medium," Chemical Engineering Journal, vol. 235, pp. 100-108, 2014.
[11] C. Travis and C. Doty, "ES\&T views: can contaminated aquifers at superfund sites be remediated?" Environmental Science \& Technology, vol. 24, no. 10, pp. 1464-1466, 1990.

[12] S. Inazumi, "Waste sludge barrier for landfill cover system," Doctoral thesis, Kyoto University, Kyoto, Japan, 2003.

[13] E. Koda, "Influence of vertical barrier surrounding old sanitary landfill on eliminating transport of pollutants on the basis of numerical modeling and monitoring results," Polish Journal of Environmental Studies, vol. 21, no. 4, pp. 929-935, 2012.

[14] T. Abichou, C. H. Benson, and T. B. Edil, "Foundry green sands as hydraulic barriers: field study," Journal of Geotechnical and Geoenvironmental Engineering, vol. 128, no. 3, 2002.

[15] A. Bezzar, D. François, and F. Ghomari, "Geochemical study of clays used as barriers in landfills," Comptes Rendus Geoscience, vol. 342, no. 9, pp. 695-700, 2010.

[16] T. Sarabian and M. T. Rayhani, "Hydration of geosynthetic clay liners from clay subsoil under simulated field conditions," Waste Management, vol. 33, no. 1, pp. 67-73, 2013.

[17] A. A. H. Faisal, M. M. Ibreesam, N. Al-Ansari, L. A. Naji, M. Naushad, and T. Ahamad, "COMSOL multiphysics 3.5a package for simulating the cadmium transport in the sand bed-bentonite low permeable barrier," Journal of King Saud University-Science, vol. 32, no. 3, pp. 1944-1952, 2020.

[18] A. A. H. Faisal, A. H. Sulaymon, and Q. M. Khaliefa, “A review of permeable reactive barrier as passive sustainable technology for groundwater remediation," International Journal of Environmental Science and Technology, vol. 15, no. 5, pp. 1123-1138, 2018.

[19] T. A. Waly, A. M. Dakroury, G. O. El-Sayed, and S. A. ElSalam, "Assessment removal of heavy metals ions from wastewater by cement kiln dust (CKD)," Journal of American Science, vol. 6, no. 12, pp. 910-917, 2010.

[20] J. Wantanaphong, S. J. Mooney, and E. H. Bailey, "Natural and waste materials as metal sorbents in permeable reactive barriers (PRBs)," Environmental Chemistry Letters, vol. 3, no. 1, pp. 19-23, 2005.

[21] A. N. Golab, M. A. Peterson, and B. Indraratna, "Selection of potential reactive materials for a permeable reactive barrier for remediating acidic groundwater in acid sulphate soil terrains," Quarterly Journal of Engineering Geology and Hydrogeology, vol. 39, no. 2, pp. 209-223, 2006.

[22] G. Cappai, G. De Gioannis, A. Muntoni, D. Spiga, and J. J. P. Zijlstra, "Combined use of a transformed red mud reactive barrier and electrokinetics for remediation of $\mathrm{Cr} /$ As contaminated soil," Chemosphere, vol. 86, no. 4, pp. 400-408, 2012.

[23] A. H. Sulaymon, A. A. H. Faisal, and Z. T. Abd Ali, "Performance of granular dead anaerobic sludge as permeable reactive barrier for containment of lead from contaminated groundwater," Desalination and Water Treatment, vol. 56, no. 2, pp. 327-337, 2015.

[24] A. A. H. Faisal and Z. T. A. Ali, "Using granular dead anaerobic sludge as permeable reactive barrier for remediation of groundwater contaminated with phenol," Journal of Environmental Engineering, vol. 141, no. 4, Article ID 04014072, 2015.

[25] A. A. H. Faisal and Z. T. Abd Ali, "Using sewage sludge as a permeable reactive barrier for remediation of groundwater contaminated with lead and phenol," Separation Science and Technology, vol. 52, no. 4, pp. 732-742, 2017. 
[26] S. S. Alquzweeni and A. A. H. Faisal, "Possibility of using granular iron slag by-product as permeable reactive barrier for remediation of simulated water contaminated with lead ions," Desalination and Water Treatment, vol. 178, pp. 211-219, 2020.

[27] A. Faisal and M. D. Ahmed, "Remediation of groundwater contaminated with copper ions by waste foundry sand permeable barrier," Journal of Engineering, vol. 20, pp. 62-77, 2014.

[28] A. A. H. Faisal, T. R. Abbas, and S. H. Jassam, "Removal of zinc from contaminated groundwater by zero-valent iron permeable reactive barrier," Desalination and Water Treatment, vol. 55, no. 6, pp. 1586-1597, 2015.

[29] A. H. Sulaymon, A. A. H. Faisal, and Q. M. Khaliefa, "Cement kiln dust (CKD)-filter sand permeable reactive barrier for the removal of $\mathrm{Cu}$ (II) and $\mathrm{Zn}$ (II) from simulated acidic groundwater," Journal of Hazardous Materials, vol. 297, pp. 160-172, 2015.

[30] A. A. H. Faisal, "Effect of $\mathrm{pH}$ on the performance of olive pips reactive barrier through the migration of copper-contaminated groundwater," Desalination and Water Treatment, vol. 57, no. 11, pp. 4935-4943, 2016.

[31] A. A. H. Faisal, Z. S. Nassir, L. A. Naji, M. Naushad, and T. Ahamad, "A sustainable approach to utilize olive pips for the sorption of lead ions: numerical modeling with aid of artificial neural network," Sustainable Chemistry and Pharmacy, vol. 15, Article ID 100220, 2020.

[32] A. A. H. Faisal, S. F. A. Al-Wakel, H. A. Assi, L. A. Naji, and M. Naushad, "Waterworks sludge-filter sand permeable reactive barrier for removal of toxic lead ions from contaminated groundwater," Journal of Water Process Engineering, vol. 33, Article ID 101112, 2020.

[33] A. A. H. Faisal, I. M. Ali, L. A. Naji, H. M. Madhloom, and N. Al-Ansari, "Using different materials as permeable reactive barrier for remediation of groundwater contaminated with landfill's leachate," Desalination and Water Treatment, vol. 175, pp. 152-163, 2020.

[34] M. A. Mastella, E. S. Gislon, F. Pelisser et al., "Mechanical and toxicological evaluation of concrete artifacts containing waste foundry sand," Waste Management, vol. 34, no. 8, pp. 14951500, 2014.

[35] A. Torres, L. Bartlett, and C. Pilgrim, "Effect of foundry waste on the mechanical properties of Portland cement concrete," Construction and Building Materials, vol. 135, pp. 674-681, 2017.

[36] B. Bhardwaj and P. Kumar, "Waste foundry sand in concrete: a review," Construction and Building Materials, vol. 156, pp. 661-674, 2017.

[37] N. Gurumoorthy and K. Arunachalam, "Micro and mechanical behaviour of treated used foundry sand concrete," Construction and Building Materials, vol. 123, pp. 184-190, 2016.

[38] J. M. Khatib, B. A. Herki, and S. Kenai, "Capillarity of concrete incorporating waste foundry sand," Construction and Building Materials, vol. 47, pp. 867-871, 2013.

[39] S. Wang, Z. Nan, Y. Li, and Z. Zhao, "The chemical bonding of copper ions on kaolin from Suzhou, China," Desalination, vol. 249, no. 3, pp. 991-995, 2009.

[40] L. Ujfaludi, "Longitudinal dispersion tests in non-uniform porous media," Hydrological Sciences Journal, vol. 31, no. 4, pp. 467-474, 1986.

[41] O. Hamdaoui and E. Naffrechoux, "Modeling of adsorption isotherms of phenol and chlorophenols onto granular activated carbonPart II. Models with more than two parameters," Journal of Hazardous Materials, vol. 147, no. 1-2, pp. 401-411, 2007.

[42] K. Y. Foo and B. H. Hameed, "Insights into the modeling of adsorption isotherm systems," Chemical Engineering Journal, vol. 156, no. 1, pp. 2-10, 2010.

[43] C. W. Fetter, Contaminant Hydrogeology, Prentice-Hall, Upper Saddle River, NJ, USA, 2nd edition, 1999.

[44] L. A. Naji, S. H. Jassam, M. J. Yaseen, A. A. H. Faisal, and N. Al-Ansari, "Modification of Langmuir model for simulating initial $\mathrm{pH}$ and temperature effects on sorption process," Separation Science and Technology, pp. 1-8, 2019.

[45] A. A. H. Faisal and M. D. Ahmed, "Removal of copper ions from contaminated groundwater using waste foundry sand as permeable reactive barrier," International Journal of Environmental Science and Technology, vol. 12, no. 8, pp. 26132622, 2015.

[46] R. L. P. Carnin, M. V. Folgueras, R. R. Luvizão, S. L. Correia, C. J. Da Cunha, and R. S. Dungan, "Use of an integrated approach to characterize the physicochemical properties of foundry green sands," Thermochimica Acta, vol. 543, pp. 150-155, 2012.

[47] M. Naushad, G. Sharma, A. Kumar et al., "Efficient removal of toxic phosphate anions from aqueous environment using pectin based quaternary amino anion exchanger," International Journal of Biological Macromolecules, vol. 106, pp. 1-10, 2018.

[48] M. Naushad, A. A. Alqadami, Z. A. AlOthman, I. H. Alsohaimi, M. S. Algamdi, and A. M. Aldawsari, "Adsorption kinetics, isotherm and reusability studies for the removal of cationic dye from aqueous medium using arginine modified activated carbon," Journal of Molecular Liquids, vol. 293, Article ID 111442, 2019.

[49] D. N. Ahmed, A. A. H. Faisal, S. H. Jassam, L. A. Naji, and M. Naushad, "Kinetic model for $\mathrm{pH}$ variation resulted from interaction of aqueous solution contaminated with nickel ions and cement kiln dust," Journal of Chemistry, vol. 2020, Article ID 8732308, 11 pages, 2020.

[50] H. B. Bradl, "Adsorption of heavy metal ions on soils and soils constituents," Journal of Colloid and Interface Science, vol. 277, no. 1, pp. 1-18, 2004.

[51] N. Saad, Z. T. Abd Ali, L. A. Naji, A. A. A. H. Faisal, and N. AlAnsari, "Development of Bi-Langmuir model on the sorption of cadmium onto waste foundry sand: effects of initial $\mathrm{pH}$ and temperature," Environmental Engineering Research, vol. 25, no. 5, pp. 677-684, 2019.

[52] S. Xing, M. Zhao, and Z. Ma, "Removal of heavy metal ions from aqueous solution using red loess as an adsorbent," Journal of Environmental Sciences, vol. 23, no. 9, pp. 14971502, 2011.

[53] M. M. Benjamin, R. S. Sletten, R. P. Bailey, and T. Bennett, "Sorption and filtration of metals using iron-oxide-coated sand," Water Research, vol. 30, no. 11, pp. 2609-2620, 1996.

[54] M. Khebchareon, "Crank-Nicolson finite element for 2-D groundwater flow, advection-dispersion and interphase mass transfer: I. model development," International Journal of Numerical Analysis and Modeling, Series B, vol. 3, no. 2, pp. 109-125, 2012. 